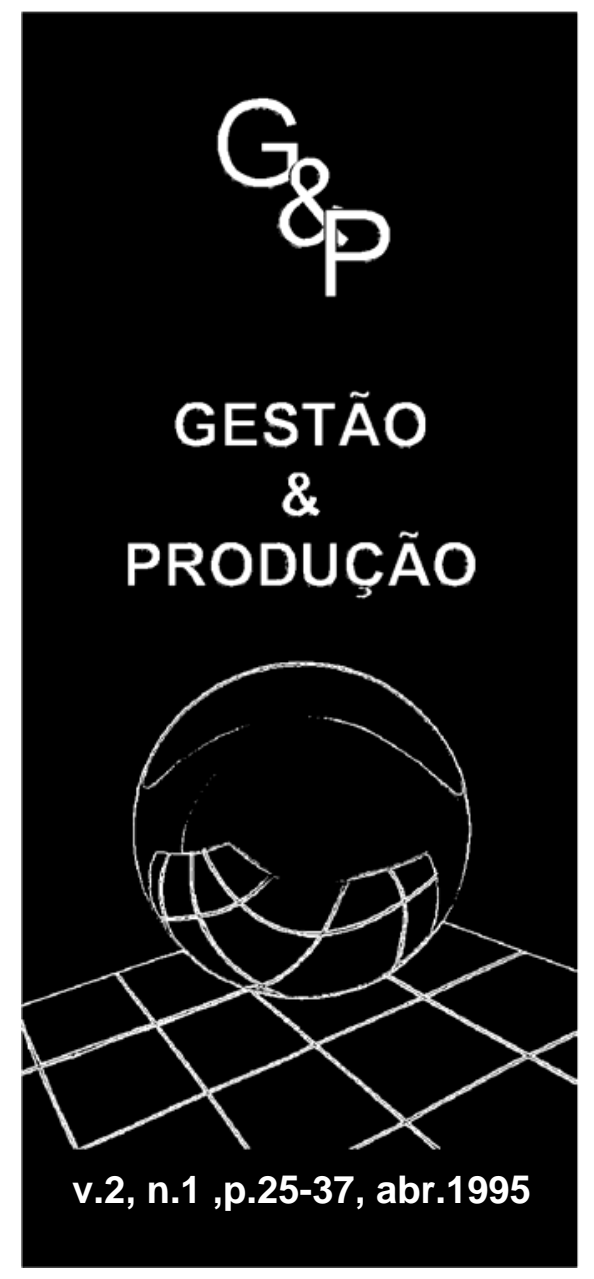

\title{
PRODUTIVIDADE FABRIL II - MÉTODO PARA RÁPIDO AUMENTO DA \\ PRODUTIVIDADE FABRIL: REDUÇÃO DE ESPERAS DENTRO DO CICLO DA OPERAÇÃO
}

\author{
José Celso Contador \\ Professor Livre-Docente do \\ Departamento de Engenharia de Produção da \\ Faculdade de Engenharia de Guaratinguetá da UNESP \\ Av. Ariberto Pereira da Cunha, 333 - Caixa Postal 205 \\ 12.500-000 Guaratinguetá - SP \\ Tel: (0125) 22-2800 R.189 \\ Ex-Prof. Dr. da Escola de Engenharia de São Carlos da USP \\ e Consultor Industrial
}

\section{Resumo}

O método para rápido aumento da produtividade fabril, aplicável principalmente à indústria brasileira de manufatura (17\% do PIB), fundamenta-se exclusivamente na redução ou eliminação do tempo inativo do homem, da máquina e do material, que é a grande causa da ineficiência. O método exige a utilização de apenas cinco das mais simples, elementares e conhecidas técnicas e é aplicável às vinte situações mais freqüentes (objetos de estudo) na indústria de manufatura. Nossa experiência atesta que o método é capaz de aumentar a produtividade fabril em valor superior a $30 \%$, em poucos meses e de forma perene (houve um caso de aumento de $160 \%$ em toda uma seção de usinagem de uma empresa multinacional). Sua aplicação e a implantação das medidas dele decorrentes são feitas com extrema facilidade e, por isto, os resultados surgem muito rapidamente. Atinge portanto seu objetivo: proporcionar aumento da produtividade fabril em curto espaço de tempo. Este artigo detalhará sete objetos de estudo (situações): 1.redução da espera da máquina durante as inspeções; 2.redução da espera do operário, abordando trabalho em equipe, produção em linha e operação com ajudante; e 3.redução da espera do operador de máquina, por meio da diminuição do tempo-máquina, do controle do tempo-máquina e da atribuição de outras atividades ao operador pela adoção da célula de manufatura.

Palavras-chave: produtividade fabril, tempo inativo, piso-de-fábrica, carta de atividades múltiplas, produção em linha, célula de manufatura. 


\section{Colocação do Problema}

O método para rápido aumento da produtividade fabril, apresentado no artigo anterior, estabelece, para cada objeto de estudo, três etapas:

1- fazer um diagnóstico expedito que quantifique a potencialidade de ganhos de produtividade e defina a ordem de prioridade dos estudos a serem elaborados para aumentar a produtividade;

2- proceder ao estudo, com instrumentos de resposta rápida, propondo soluções aos problemas diagnosticados; e

3- testar, obter a aprovação da gerência e implantar as soluções.

Cada etapa, por sua vez, é cumprida por meio de quatro subetapas: objetivo, estraté-gia, técnica e procedimento.

O método estabelece também os vinte objetos de estudo, ou seja, os problemas mais freqüentemente encontrados no pisode-fábrica da indústria brasileira de manufa-tura que criam óbices à fabricação em nível adequado e possível de produtividade.

A etapa do diagnóstico, subdividida nas suas quatro subetapas, foi tratada no artigo anterior. Os vinte objetos de estudo serão detalhados neste e no próximo artigo.

Cabe, neste artigo, analisar os três primeiros grupos de objetos de estudo, cujo objetivo é aumentar a produtividade pela redução das esperas que ocorrem dentro do ciclo da operação. São eles:

1- redução da espera da máquina durante as inspeções;

2- redução da espera do operário no trabalho grupal ou interdependente, abordando três tipos de situação:

2a. trabalho em equipe;

2b. produção em linha; e

2c. operação com ajudante; e

3- redução da espera do operador de máquina por meio da:

3a. diminuição do tempo-máquina;

3b. controle do tempo-máquina; e

3c. atribuição de outras atividades ao operador.

Convém lembrar que o diagnóstico de todos estes problemas é feito de acordo com as técnicas apresentadas no artigo anterior.

\section{Carta de Atividades Múltiplas}

$\mathrm{O}$ instrumento adequado para analisar a possibilidade de reduzir esperas dentro do ciclo da operação é a carta de atividades múltiplas. Portanto, preliminarmente, é necessário recordar seus conceitos.

Carta de atividades múltiplas é um instrumento gráfico destinado à análise das atividades simultaneamente executadas por vários agentes, quer homens, quer máquinas. Representa, num gráfico em escala, as atividades de cada agente numa coluna.
Deve-se afirmar, desde já, que, na maioria dos casos, sua elaboração é dispensável, pois a simples utilização de seus conceitos é suficiente para conduzir o raciocínio na direção da redução das esperas dentro do ciclo da operação.

BARNES (1977) distingue apenas ativida-de e não-atividade (espera). G. REICHERT (1969) já distingue três tipos de atividades:

\begin{tabular}{|c|c|c|}
\hline Atividades & Para o operador & Para a máquina \\
\hline Independente & $\begin{array}{l}\text { Qualquer trabalho que for independente } \\
\text { da(s) máquina(s) ou de outro(s) operador(es) }\end{array}$ & $\begin{array}{l}\text { Qualquer trabalho efetuado pela máquina } \\
\text { sem ajuda do homem }\end{array}$ \\
\hline Espera & $\begin{array}{l}\text { Esperando pela(s) máquina(s) ou pelo traba- } \\
\text { lho de outro(s) operador(es) }\end{array}$ & Esperando pelo(s) operador(es) \\
\hline Combinada & $\begin{array}{l}\text { Trabalho efetuado em conjunto com máqui- } \\
\text { na(s) ou com operador(es) }\end{array}$ & $\begin{array}{l}\text { Sendo atendida por operador(es), ou } \\
\text { trabalhando acoplada ou em conjunto com } \\
\text { outra(s) máquina(s) }\end{array}$ \\
\hline
\end{tabular}




\section{Redução da Espera da Máquina Durante as Inspeções}

É da essência do trabalho, o executor ser responsável pela qualidade da sua obra. O artesão medieval e os antigos já assim agiam. A filosofia da produção em massa, deslocando a inspeção para o final da linha de produção e aceitando a "inevitabilidade" de certa porcentagem de defeitos, acabou por amortecer a importância da responsabi-lidade do operário pela qualidade do seu serviço. Mas, recentemente, os japoneses a revigoraram.

De forma inquestionável, cabe pois ao trabalhador de hoje o dever de produzir com qualidade. Para tanto, a inspeção do produto de sua atividade deve fazer parte integrante do ciclo de trabalho: imediatamente após a conclusão da operação que lhe toca, o operário deve verificar se o que executou está de acordo com as especificações.

Esta norma, levada ao pé da letra, acaba por introduzir uma espera da máquina dentro do ciclo de trabalho: terminada a atividade da máquina, o operador desligaa, retira a peça, inspeciona-a, coloca-a de lado, apanha outra peça, alimenta a máquina, liga-a e (quase sempre) fica esperando a máquina cumprir sua função.

O tempo consumido numa inspeção pode chegar a $10 \%$, ou mais, da duração do ciclo, nos casos de inspeções mais com-plexas em ciclos curtos; nas mais simples, em ciclos longos, não ultrapassa 3\% ou 4\%.

É um tempo eliminável. Basta fazer a inspeção durante o período em que a máquina esteja processando a peça seguinte. Assim, terminada a atividade da máquina, o operador desliga-a, retira a peça, colocaa de lado, apanha outra peça, alimenta a má-quina, liga-a, e, só então, inspeciona a peça retirada.

Essa simples postergação da inspeção, que reduz a duração do ciclo, pode representar um aumento importante na produtividade da máquina: de $11 \%$, se a inspeção corresponder a $10 \%$ do ciclo de produção, por exemplo.

Por que essa postergação não é feita na enorme maioria das nossas fábricas? Por que é difundido o conceito de que se uma peça foi produzida fora das especificações, a seguinte também o será. O argumento procede. Entretanto, deve-se considerar que o custo da rejeição de uma peça adicional é largamente compensado pela economia decorrente do aumento da produtividade. Isto só não ocorre nos raros casos onde o custo da rejeição é bastante alto, e pequena a diminuição do ciclo de produção.

Portanto, a regra geral pode ser assim enunciada: fazer a inspeção de uma peça durante 0 tempo-máquina da peça seguinte; se a peça estiver fora das especificações, e a seguinte também, proceder aos neces-sários ajustes e correções na máquina.

O tempo inativo da máquina durante a inspeção é detectado pela amostragem do trabalho, na etapa do diagnóstico abordada no artigo anterior. Requer, porém, um estudo mais detalhado, que deve ser feito por meio de uma carta de atividades múltiplas.

\section{Redução da Espera do Operário no Trabalho Grupal ou Interdependente}

Nas situações em que dois ou mais elementos participam de uma mesma operação ou de operações interdependentes, e no caso um elemento pode ser a máquina ou o homem, sempre haverá alguns elementos esperando. A não ser na circunstância em que os ciclos de trabalho de todos os ele- mentos sejam iguais, isto é, numa operação perfeitamente balanceada, vários elementos ficam parados, esperando o de maior ciclo completar sua tarefa. E o tempo de espera de cada elemento é exatamente igual à diferença entre a duração do maior ciclo e a duração do seu ciclo de trabalho. 
Como as operações perfeitamente balan-ceadas são raras, pode-se enunciar, como regra geral, que sempre haverá espera quan-do dois ou mais elementos participam de

uma mesma operação ou de operações interdependentes. Os casos mais freqüentes encontrados na indústria brasileira de manufatura e que merecem ser discutidos aqui são:

a) equipe de operários executando uma mesma operação;

b) produção em linha; e

c) operação com ajudante.

\subsection{Trabalho em equipe}

Para reduzir as esperas, nas situações em que vários operários participam da mes-ma operação, basta dimensionar o tamanho da equipe. Esse dimensionamento consiste numa aplicação direta dos resultados da etapa de diagnóstico do método para rápido aumento da produtividade fabril; mais precisamente, da subetapa de iden-tificação dos tempos inativos, cujo proce-dimento foi descrito na subseção 9.7 do artigo anterior.

Os passos de números 6 e 7 desse procedimento, uma variação da amostragem do trabalho, estabelecem:

6. Calcular a média e o desvio-padrão da quantidade de operários em cada equipe de trabalho, ou da freqüência relativa nos ca-sos em que a máquina e/ou o operário são unitários.

7. Corrigir os valores da média e do desvio-padrão, pelos fatores de equalização da produção e do ritmo, dividindo-os pelo primeiro e multiplicando-os pelo segundo (Lembre-se que multiplicando-se por uma constante os valores de uma variável alea-tória, a média ficará multiplicada pela mesma constante, e a variância ficará multi-plicada pelo quadrado da constante (LEME,. 1963).
A média corrigida já corresponde à dimensão média da equipe. Se durante o diagnóstico for constatada a possibilidade da introdução de melhorias no método de trabalho (como eliminação ou simplificação de movimentos, mudança do lay-out do local de trabalho, alteração de ferramentas ou dispositivos etc), deve-se utilizar esse valor médio. Se essa possibilidade não tiver sido visualizada, deve-se adotar um coefi-ciente de segurança; em muitos casos, a média mais metade do desvio-padrão, cor-rigidos, dão a dimensão adequada da equi-pe de trabalho.

O exemplo seguinte é ilustrativo.

A operação de embalar produtos, executada por uma equipe de 8 homens, foi dividida em 6 elementos:
a- contar e pesar;
b- arrumar e amarrar;
c- embrulhar;
d- etiquetar;
e- homens parados; e
f- homens ausentes.

Foram feitas 20 rondas, anotando-se a quantidade de operários que executava cada elemento. Os resultados estão na tabela seguinte.

\begin{tabular}{|c|c|c|c|c|c|c|c|c|c|c|c|c|c|c|c|c|c|c|c|c|}
\hline \multicolumn{11}{c|}{ QUANTIDADE DE HOMENS EM CADA ELEMENTO } \\
\hline \multirow{2}{*}{ ELEMENTO } & 1 & 2 & 3 & 4 & 5 & 6 & 7 & 8 & 9 & 10 & 11 & 12 & 13 & 14 & 15 & 16 & 17 & 18 & 19 & 20 \\
\hline a & & & & & & & & & & & & & 1 & & 2 & & & & 2 & 2 \\
\hline $\mathrm{b}$ & 8 & 4 & 8 & & & 6 & 6 & 8 & & & 4 & 5 & & 4 & & 4 & 6 & 6 & & 2 \\
\hline $\mathrm{c}$ & & 4 & & & 4 & & & & 5 & & & & 5 & 4 & 4 & 4 & & & 4 & 4 \\
\hline $\mathrm{d}$ & & & & & & & & & 2 & & & 1 & & & & & 1 & 1 & 1 & \\
\hline
\end{tabular}




\begin{tabular}{|c|c|c|c|c|c|c|c|c|c|c|c|c|c|c|c|c|c|c|c|c|}
\hline $\mathrm{e}$ & & & & 88 & \begin{tabular}{|l|}
4 \\
\end{tabular} & 2 & 2 & & & 8 & 4 & & & & & & & & & \\
\hline $\mathrm{f}$ & & & & & & & & & 1 & & & 2 & 2 & & 2 & & 1 & 1 & 1 & \\
\hline ativic & 8 & 8 & 8 & 0 & 4 & 6 & 6 & 8 & 7 & 0 & 4 & 6 & 6 & 8 & 6 & 8 & 7 & 7 & 7 & \\
\hline
\end{tabular}

Apesar de a operação ter sido dividida em quatro suboperações, interessa, no caso, apenas o comportamento do conjunto dos oito homens, uma vez que atuavam de forma intercambiável, cada um podendo efetuar uma suboperação qualquer. Assim, basta considerar tão somente a quantidade de homens em atividade, conforme mostrado a seguir, onde estão subjacentes o fator de equalização da produção de $80 \%$ e o fator de equalização do ritmo de $85 \%$ :

\section{HOMENS EM ATIVIDADE}

média
desvio-padrão
média corrigida
desvio-padrão corrigido

A partir dos dados obtidos na amostragem do trabalho e dos fatores de equalização, conclui-se que a equipe deveria ser constituída por 7 homens (6,48 em média), ou quiçá 6 homens, se a possibilidade da introdução de melhoria no método de tra-
6,10 homens

2,43 homens

6,48 homens

2,58 homens

balho for alta. Caso deseje-se operar com uma margem de segurança, deve-se acrescentar metade do desvio-padrão corrigido, o que daria 8 homens (7,77 para ser preciso).

\subsection{Produção em linha}

Na produção em linha, quando as operações são feitas sucessivamente, ou seja, uma imediatamente após a anterior sem a formação de estoque intermediário de peças, sempre haverá espera de alguns elementos (homens e/ou máquinas) se a duração das operações não estiver balanceada.

Para eliminar ou reduzir as esperas, dois caminhos devem ser tentados: integrar totalmente os operários, formando uma só equipe, cujos elementos se auxiliem mutua-mente; ou desvincular totalmente uma ope-ração da anterior, eliminando o conceito de produção em linha. Como se vê, esses dois caminhos representam soluções completa-mente opostas, e a adoção de um deles dependerá das características do trabalho. Dois casos ilustram a idéia.

\section{Integração dos operários numa só equipe}

Em uma fábrica de produtos extrudados de alumínio (perfis), existiam duas prensas, nas quais trabalhavam 20 homens, 10 em cada prensa, assim distribuídos:

3 homens fixos para operar a prensa;

2 homens para estirar os perfis;

2 homens para arrumar os perfis na mesa da prensa; e

3 homens para serrar os perfis no com primento encomendado.
Caso se considerem essas quatro operações isoladamente, constata-se que é absolutamente necessária essa quantidade de ope-rários em cada operação. Mas, o diagnóstico feito de acordo com o método descrito no artigo anterior - uma variação da amostragem do trabalho - evidencia esperas relativamente grandes desses operários. Pa-ra reduzí-las, imaginou-se uma completa integração entre os 
esticadores, arrumado-res e serradores das duas prensas, um total de 14 homens. Excluíram os 3 operadores de cada prensa, pois eles não podem aban-donar seus postos de trabalho já que a prensa, possuindo dois porta-ferramentas, trabalha ininterruptamente, sendo a coloca-ção da ferramenta a ser utilizada feita du-rante a prensagem do perfil anterior.

Dimensionada, pelo método mostrado na subseção anterior, a equipe necessária

para as operações de estiragem, arrumação e serração, concluiu-se que bastariam 10 operários, economizando-se 4, o que representa um aumento de $40 \%$ na produtividade dos 14 homens, ou de 25\% na produtividade dos 20 homens. Para viabilizar este ganho, seria necessário apenas que a arrumação dos perfis na mesa da prensa fosse feita por 5 homens (2 estiradores e 3 serradores), o que consumiria um tempo bem menor do que aquele gasto pelos 2 arrumadores. Além disso, ficou estabelecido que os operários de uma prensa deveriam auxiliar seus colegas da outra sempre que necessário e possível, o que permitia que, às vezes, 7 ou 8 pessoas estivessem arrumando os perfis na mesa.

Para a precisão do diagnóstico, foi fundamental o uso dos fatores de equalização da produção e do ritmo, pois, como uma extrusão trabalha num regime quase justin-time, a sua produção, em toneladas, varia de dia para dia, tanto em função do programa de produção como do mix de produto medido em peso por metro. Por esta razão, nos dias de baixa produção, a tendência dos operários é ralentar seu ritmo. Daí a necessidade de corrigir o tempo dedicado pelo operário à sua atividade pelos fatores de equalização da produção e do ritmo.

\section{Eliminação da produção em linha}

Numa fundição, as diversas operações necessárias à rebarbação de uma peça eram feitas em quatro mesas, cada uma dotada de esteira transportadora, em que trabalhavam onze operários: um na cabeceira, que fazia a primeira operação e alimentava a esteira, e cinco de cada lado; ao chegar no final da esteira, a peça estava rebarbada. Como todas as peças fundidas passavam por uma mesa de rebarbação, e como o tempo de cada operação variava muito em função da geometria da peça, era impossível balancear os tempos das operações. Conseqüentemente, sempre havia operários esperando outros concluírem sua operação. E a velocidade da esteira, controlada pelo operário da cabeceira, era determinada pela operação de maior ciclo, ou seja, a produ-ção de dez dos onze homens era limitada por aquele que mais demorava.

Para a precisão do diagnóstico, muito contribuiu o fator de equalização do ritmo. Como o operário reduzia naturalmente seu ritmo quando uma das operações anteriores era mais lenta, nem sempre se visualizavao parado - estava em atividade, mas lentamente. Foi pois fundamental avaliar o ritmo de cada operário em cada peça. Com este cuidado, o diagnóstico, feito por meio da variação da amostragem de trabalho des-crita no artigo anterior, permitiu concluir que, se as operações fossem desvinculadas, 30 operários fariam a produção dos 44 (11 em cada mesa).

Assim, as quatro mesas-esteiras foram retiradas da fábrica e substituídas por 30 bancadas individuais, uma por operário, que passou a fazer uma única operação numa peça. Em decorrência, a produção deixou de ser em linha, para ser em lotes. Apesar de esta solução ter criado estoques intermediários às operações, o ganho de produtividade na rebarbação foi enorme: $46 \%$. E, note-se, sem necessidade de modificar o método de trabalho do operário, sem exigir treinamento; mudado o lay-out, o aumento de produtividade foi imediato. 
Muitas operações na indústria de manufatura são executadas por um operador e um ajudante. Em algumas, o ajudante é realmente necessário, como no estiramento de perfis de alumínio citado na subseção anterior - o ajudante prende uma ponta do

perfil no mordente enquanto o operador, a mais de 30 metros de distância, fixa a outra ponta no mordente da estiradeira e acionaa. Mas, em outras operações, o ajudante é dispensável.Para analisar a possibilidade de eliminar o ajudante, é necessário, em primeiro lugar, verificar se operador e ajudante trabalham próximos um do outro, pois, se a distância que os separa for grande, o tempo consu-mido pelo operador no deslocamento de um posto de trabalho para outro anularia os ganhos de produtividade que seriam obti-dos pela eliminação do ajudante. Em se-gundo lugar, é necessário construir uma carta de atividades múltiplas, mostrada na seção inicial, a fim de verificar se um homem, apenas, teria condições de execu-tar a operação sem prejudicar a quantidade produzida.

O seguinte caso é ilustrativo.

Numa fábrica extrusora de perfis metálicos, a liga desejada é obtida pela adição de elementos ao metal fundido, e o produto dessa refusão tem a forma cilíndrica, com 15 ou 20 centímetros de diâmetro por alguns metros de comprimento. Em função do peso por metro do perfil e do número de orifícios da ferramenta da prensa extrusora, é dimensionado o comprimento do tarugo que, uma vez extrudado, produza perfis de um comprimento pré-determinado. Por isto, o tarugo que sai da refusão precisa ser serrado no comprimento adequado à ope-ração de extrusão.

Na operação de serração do tarugo trabalhavam dois homens, o operador e o ajudante. Construída a carta de atividades múltiplas, constatou-se que quando um estava em atividade, o outro quase sempre estava parado, evidenciando que bastaria um para executar o trabalho. Mas, como cada um trabalhava de um lado da serra, foi necessário, para viabilizar a eliminação do ajudante, transferir o painel de controle da serra para o lado por onde saía o tarugo serrado. Com esta simples modificação, o ajudante tornou-se dispensável, a produtividade da máquina foi conservada e a do homem, duplicada.

Os dados obtidos no diagnóstico, feito por uma variação da amostragem do trabalho, são úteis também para a análise da viabilidade da eliminação do ajudante, porque, em alguns casos, essa eliminação pode implicar a introdução de esperas na má-quina: se a média do tempo de atividade do operador e do ajudante for maior que a me-tade da duração do tempomáquina, a eli-minação do ajudante provocará um tempo-homem maior que $100 \%$, obrigando que o novo ciclo de atividade seja este valor, isto é, a máquina terá que esperar o operador concluir seu ciclo. Necessário verificar, en-tão, se é viável a máquina perder pro-dutividade em decorrência do aumento do seu ciclo.

No exemplo citado, o diagnóstico evidenciou que a serra de tarugo estava em operação durante pouco menos de $80 \%$ do tempo, já considerados os fatores de equalização da produção e do ritmo.Este valor significava que a eliminação do ajudante poderia causar um aumento de até $25 \%$ na duração do ciclo de trabalho, pois, até esse valor, a serra teria capacidade para atender às necessidades de produção.

Conclusão: devido à freqüência de ocorrência de operação com ajudante, devido à alta probabilidade da eliminação do ajudante e devido aos altos ganhos de produtividade acarretados pela eliminação de um homem, recomendamos: sempre que houver ajudante numa operação, analisar a possi-bilidade de sua eliminação.

Para tanto, deve-se:

1) verificar se operador e ajudante traba-lham suficientemente próximos; 
2) verificar, por meio de uma carta de atividades múltiplas, se os períodos de ativi-dade de ambos são defasados a ponto de permitir ao operador realizar as atividades do ajudante;

3) verificar, por meio de uma carta de atividades múltiplas, se a operação com apenas um homem implica aumento do ciclo de

trabalho devido à necessidade de a máquina esperar o homem;
4) verificar, a partir dos dados do diagnóstico, se a máquina dispõe de tempo inativo suficiente para suportar um eventual aumento da duração do ciclo de trabalho;

5) verificar se a eliminação do ajudante exige alterações na máquina e no local de trabalho; e

6) analisar a viabilidade econômica da eliminação do ajudante, confrontando a economia decorrente do aumento de produtividade com o investimento necessário à implementação das modificações.

\section{Redução da Espera do Operador de Máquina}

Situação das mais freqüentes na empresa manufatureira brasileira: operador parado esperando a máquina executar seu trabalho. Numa fresadora, por exemplo, o operador retira a peça recém-usinada, limpa a má-quina e o dispositivo com ar comprimido e coloca outra peça para ser usinada, con-sumindo menos de um minuto; a máquina, para usinar a peça, demora vários minutos, durante os quais o operador nada faz. Ou seja, em muitas operações, o homem tra-balha menos do que $20 \%$ do tempo do ci-clo da operação. (Os tempos de atividade e de espera são quantificáveis pela amos-tragem do trabalho durante o diagnóstico, conforme discutido no artigo anterior).

Sendo alta a percentagem de espera do operador, alta é a potencialidade de aumen-to da sua produtividade. Como conseguí-lo, é o objeto desta seção, na qual três re-comendações são analisadas:

1. diminuir o tempo-máquina;

2. controlar o tempo-máquina; e

3. atribuir outras atividades ao operador.

As duas primeiras, além de aumentar a produtividade do homem, aumentam também a da máquina.

\subsection{Diminuição do tempo-máquina}

Caso se consiga diminuir o tempo de operação da máquina, denominado tempomáquina ou tempo automático, diminuirse-á o tempo de espera do operador. Isto é possível em muitas situações. Veja-se o caso de uma usinagem.

As variáveis determinantes do tempo e da qualidade de uma usinagem, como velocidade de corte, profundidade de corte, velocidade de avanço, ângulos, forma e ma-terial da ferramenta de corte etc., são conhecidas há muito tempo. Não obstante a otimização das condições de usinagem ser trivial, pois a solução está reduzida à sim-ples aplicação de fórmulas matemáticas, a determinação das variáveis está, na maioria das empresas, entregue ao operador - só em algumas, nas maiores, a Engenharia de Processo cuida de determiná-las. É de se esperar, portanto, que as variáveis não estejam otimizadas.

Nesta situação, é possível aumentar a velocidade de avanço da máquina e, em decorrência, diminuir o tempo automático, o que reduzirá o tempo de espera do operador.

Devido ao espírito das medidas discutidas nesta série de artigos - medidas para um rápido aumento da produtividade-, não cabe propor a otimização das condições de usinagem pelas técnicas da Engenharia, 
pois estas demandam longo tempo de estudo que, multiplicado pelo grande número de operações de usinagem, exigiriam muitos meses. Cabe, portanto, apenas propor um método empírico.

Para determinar as condições de usinagem, o responsável pelo setor e o operador devem ir aumentando gradativamente as velocidades da máquina operatriz e ir observando seu nível de vibração e as dimensões e a rugosidade superficial da peça, até determinarem as máximas velo-

cidades. Após ter sido a peça aprovada pelo Controle de Qualidade, fixam essas condições de usinagem e as anotam na fo- lha de processo. Caberá, então, ao responsável pelo setor fiscalizar se essas condições são obedecidas sempre que essa peça estiver em produção.

Em muitos casos, esse procedimento ex-perimental possibilita aumentos de veloci-dade superiores a $20 \%$, reduzindo o tempo-máquina e a espera do operador.

Aumentar a velocidade da operação não é privativo do processo de usinagem; é possível em quase todos os processos típicos da indústria manufatureira, como fun-dição, extrusão, laminação, pintura, etc..

\subsection{Controle do tempo-máquina}

Em certas situações, além de reduzir o tempo-máquina, é necessário controlá-lo.

É o caso do tempo de solidificação de uma peça fundida. Este tempo, na maioria das fundições, fica a critério do fundidor, que abre a coquilha ou desmolda a caixa de areia quando julga que a peça já esteja solidificada. Cronometrando o tempo de solidificação de várias peças de idêntico produto, constata-se grande dispersão dos dados, até entre as produzidas pelo mesmo fundidor.
Cabe, portanto, nessas situações, definir o tempo mínimo de solidificação, o que se faz experimentalmente, e dar ao operário condições para atendê-lo. Para isto basta instalar um dispositivo regulador de tempo que abra a coquilha automaticamente ou que assinale a possibilidade de desmoldagem da caixa de areia.

O controle do tempo-máquina pode possibilitar ganhos de produtividade, tanto do homem quanto da máquina, superiores a $10 \%$.

\subsection{Atribuição de outras atividades ao operador}

Em muitas situações, o operador trabalha em menos de $20 \%$ do ciclo, ficando o resto do tempo à espera do tempo-máquina, como já mencionado. Atribuir outras atividades ao operador, passíveis de serem executadas no tempo automático, permitirá ganhos expressivos de produtividade do homem, várias vezes superior aos conseguidos com as duas providências anteriores, relativas à diminuição e ao controle do tempo-máquina.
A solução mais freqüente para este enriquecimento de funções é atribuir várias máquinas a um mesmo operador. No caso de duas máquinas, o ganho de produtividade do homem pode ser superior a $80 \%$. Se for possível atribuir três máquinas a um operador, esse ganho ultrapassará 100\%. Constitui-se, por esta forma, uma célula de manufatura, tema da próxima seção. 

Cabe, nesta seção, analisar a atribuição de outras atividades ao operador, o que resultará principalmente numa célula de manufatura.

Como mencionado na seção anterior, a atribuição de mais de uma máquina a um operador resulta numa célula de manufatura. Diante dos expressivos ganhos de produtividade do homem, proporcionados pela célula de manufatura - em muitos casos, superiores a $100 \%$-, e considerando que temos contribuição conceitual a apresentar, torna-se imperioso destinar uma seção ao tema.

\subsection{Os vários tipos de célula de manufatura}

A célula de manufatura, pioneiramente implantada pela Toyota no Japão, consiste numa configuração em que as máquinas são dispostas numa seqüência idêntica à das etapas do processo de fabricação de um produto, ou de uma família de produtos, definida segundo o conceito de tecnologia de grupo, e na qual, sem estoque interme-diário, procura-se, em cada vez, completar o ciclo de produção de uma peça ou pro-duto dentro de uma restrita área de trabalho.

O exemplo característico é a fabricação e acabamento de uma engrenagem. Um operário, apenas, é responsável por 16 máquinas, cada uma com uma função específica. Ele retira da primeira máquina a peça já processada, coloca a peça a ser proces-sada, apanha a peça anterior e encaminha-se para a segunda máquina, acionando a chave situada entre as duas máquinas para pôr em movimento a primeira máquina. Na segunda máquina, ele retira a peça já pro-cessada, coloca a que trouxe da primeira máquina, apanha a processada e enca-minha-se para a terceira máquina, acionan-do a chave para ligar a segunda máquina. Repete esse procedimento nas 16 máqui-nas, dispostas em forma de U, completando o ciclo em 5 minutos, o que significa que a cada 5 minutos uma engrenagem está pronta (IMAM, 1989).

Todos que pensam sobre célula de manufatura e todos os autores que dela tratam entendem por célula de manufatura algo como o conceituado "uma fábrica dentro da fábrica" (por exemplo, IMAM (1989), MONDEN (1984), SCHONBERGER (1984), HALL (1988), BEZERRA (1990),
MOURA (1989), OLIVÉRIO (1984), YOSHINAGA (1988), DIRIGENTE INDUSTRIAL $(1987,1989))$.

Entretanto, nós identificamos quatro tipos de célula de manufatura: por produto com predominância da máquina, por produto com predominância do homem, por processo e por posição fixa do produto (CONTADOR, 1991). Pelas denominações, percebe-se que esta classificação é análoga à dos tipos clássicos de lay-out.

A célula de manufatura por produto, com predominância da máquina, correspon-de ao modelo da Toyota, recém descrito, que é o tipo reconhecido por todos.

A célula de manufatura por produto, com predominância do homem, é semelhan-te à anterior, em que os postos de serviços são dispostos na seqüência das etapas do processo de fabricação de um produto ou família de produtos, de forma a completar pelo menos parte da fabricação de uma peça ou produto numa área restrita. Serve como exemplo o acabamento de peças fundidas pela execução seqüencial de três operações: rebarbação, lixação e esmerilha-ção, realizadas por um ou por três operários.

A célula de manufatura por processo corresponde ao agrupamento de operações realizadas por máquinas de mesmo tipo, como por exemplo três fresadoras operadas por um mesmo homem. Pode ser denominada também célula funcional, por agregar máquinas que têm a mesma função.

A célula de manufatura por posição fixa do produto é caracterizada pelo agrupamento de operários que trabalham em volta de um produto colocado numa posição 
fixa. É o modelo implantado pela SaabScania na fábrica de motores de Sodertalje na Suécia, onde um grupo de três operários monta um motor colocado sobre uma bancada. Corresponde também ao que a Volvo denominou grupo semi-autônomo (HILLESHEIM \& COSMO, 1988). Como este tipo de célula foi implantado e desenvolvido pioneiramente na Suécia, pode ser denominado célula sueca ou escandinava, ou, seguindo a tradição do lay-out, por célula posicional.

As células de manufatura ainda podem ser classificadas: a) em função da quantidade de modelos de produto que processam (um só modelo, uma família de produtos ou qualquer produto);

b) em função da quantidade de operários que nelas trabalham (célula individual ou célula grupal com vários operários); e

c) em função da predominância sobre o trabalho, exercida pela máquina ou pelo homem.

\subsection{Célula de manufatura por processo}

Devido às suas vantagens, a célula de manufatura por processo merece alguns comentários adicionais.

A célula de manufatura por processo é caracterizada pelo agrupamento de duas ou mais máquinas de mesmo tipo, operadas por um único homem e dispostas convenientemente de forma a minimizar os deslocamentos do operador, como, por exemplo, duas fresadoras, duas coquilhadeiras para fundição.

A finalidade precípua desta célula é aproveitar o tempo-máquina, durante o qual o operador fica parado esperando a máquina completar automaticamente seu ciclo. $\mathrm{O}$ operário pode, portanto, operar outra máquina durante o tempo automático da primeira. Está implícito que o ciclo de operação é comandado pela máquina.

Esta célula permite a fabricação de produtos de qualquer tipo, independentemente de fazerem parte da mesma família no conceito tradicional. Mas, na realidade, as peças a serem trabalhadas simultaneamente devem pertencer à família definida pelo conceito de ciclo de operação: a duração dos ciclos deve ter valores próximos entre si.

A produtividade do operário pode aumentar significativamente, dependendo da relação entre o seu tempo de atividade e a duração do ciclo total. Se o operário trabalhar simultaneamente em duas máquinas, se seu tempo de atividade for menor do que a duração do ciclo total e se a duração dos ciclos de cada peça tiver valores próximos, a produtividade do operário chegará a do-brar. Entretanto, a produtividade da má-quina de menor ciclo diminuirá, pois seu ciclo ficará igual ao da outra máquina, ou seja, ela terá que esperar esta, perdendo portanto produtividade.

Para se obter ganho significativo de pro-dutividade, é necessário definir, a partir da análise do ciclo de operação, os pares ou ternos de peças a serem processadas simul-taneamente. Ou seja, as famílias de peças serão determinadas pelo ciclo de operação. Para tanto, a técnica a ser utilizada é a da carta de atividades múltiplas, exposta no início do artigo.

A célula de manufatura por processo apresenta três vantagens extremamente importantes: proporciona significativo aumen-to da produtividade do homem, não requer operários multifuncionais e é muito fácil de ser implantada.

Os ganhos de produtividade proporcionados ao homem são impressionantes: numa usinagem, 160\%; numa coquilharia, 60\%; numa macharia, $52 \%$.

A segunda vantagem está em não requerer operários multifuncionais. Como ca-da operário trabalhará sempre no mesmo processo, não há necessidade de 
novo trei-namento. (O fresador continuará operando fresadoras, só que duas ou três, ao invés de uma).

A terceira vantagem é a facilidade de implantação. Não há necessidade de treinar operários, e a mudança da posição das máquinas é simples: basta dispô-las tangencialmente a um círculo aberto que facilite a entrada e a saída de peças. Obviamente deve haver espaço dentro da célula para cestos com peças a processar e com peças processadas.

Nós, diante destas três vantagens, a recomendamos, de forma enfática, para a fase inicial de um programa de aumento da produtividade fabril. Na verdade, ela corresponde a importante recomendação do método para rápido aumento da produtividade fabril, descrito nesta série de artigos.

\section{Referências Bibliográficas:}

BARNES, Ralph: Estudo de Movimentos e de Tempos. Edgard Blücher, São Paulo, 1977.

REICHERT, Gert. H.: Estudo de Métodos de Trabalho. Escola de Engenharia da USP, São Carlos, 1969.

LEME, Ruy A.S.: Curso de Estatística. Livro Técnico, Rio de Janeiro, 1963.

IMAM: Produtividade e Qualidade no Piso de Fábrica. Instituto de Movimentação e Armazenagem de Materiais, São Paulo, 1989.

MONDEN, Yasuhiro: Sistema Toyota de Produção. IMAM, São Paulo, 1984.

SCHONBERGER, Richard J.: Técnicas Industriais Japonesas. Pioneira, São Paulo, 1984.

HALL, Robert W.: Excelência na Manufatura. IMAM, São Paulo, 1988.

BEZERRA, J. Cavalcanti: Simples...men-te Just-in-Time. IMAM, São Paulo, 1990.

MOURA, Reinaldo A.: Kanban. IMAM, São Paulo, 1989.
OLIVÉRIO, J. Luiz: A Manufatura Celular. Segundo Seminário de Técnicas Japonesas promovido pelo IMAM. IMAM, São Paulo, 1984.

YOSHINAGA, Ciro: Qualidade Total. São Paulo, 1988.

DIRIGENTE INDUSTRIAL: "Às Vezes É Preciso Mexer no Leiaute". Dirigente Industrial (Editora Visão, São Paulo), XXVIII (11): 26-30, nov. 1987.

DIRIGENTE INDUSTRIAL: "Menor Espaço para as Máquinas". Dirigente Industrial (Editora Visão, São Paulo), XXX(5):24-25, mar. 1989.

CONTADOR, J. Celso: "Tipologia da Célula de Manufatura". Segundo Simpósio de Ciências Exatas e Engenharias da UNESP, Universidade Estadual Paulista, Campos do Jordão, dez. 1991.

HILLESHEIM, Sérgio W. \& COSMO, J. Roberto: GSA - Grupos Semiautônomos. COP Editora, Rio de Janeiro, 1988.

\section{MANUFACTURE PRODUCTIVITY II - QUICK IMPROVEMENT METHOD OF MANUFACTURE PRODUCTIVITY: WAITING REDUCTION IN THE OPERATION CICLE}




\section{ABSTRACT}

The quick improvement method of manufacture productivity is exclusively based on the reduction or elimination of the machine/operator/material inactive time. The inactive time of these three elements is recognized to be the main reason for inefficiency. The method here discussed is especially applicable to Brazilian manufacturing industry (which represents $17 \%$ of the GDP). It utilizes five of the most simple, elementary and well-known techniques and it is applicable to the most frequent situations of the manufacturing industries. The background of the author assures that the method can improve productivity by more than $30 \%$ in a short

time (in one particular enterprise, it was possible to improve by $160 \%$ the productivity of its machining department). The application of the method and the implementation of its suggested rules are made with great ease and, because of that, the results appear very quickly. The paper will datail the reduction in machine wait-time during the inspections, as well as the reduction in operator wait-time.

Key-words: manufacture productivity, inactive-time, plant level, multiple activity chart, serial production, manufacture cell. 